\title{
Effects of Alloying Copper and Silicon on the Bondability of Dissimilar Metal Joints of Aluminum Alloys to Steel*
}

\author{
by Yuichi Saito**, Hidetaka Umeshita***, Tomo Ogura****and Akio Hirose****
}

\begin{abstract}
The effects of $\mathrm{Cu}$ and $\mathrm{Si}$ in aluminum alloys on the joint properties of Aluminum alloys/steels were evaluated by correlating the interfacial microstructures with the joint strength using diffusion bonding. It was found that joint strength was improved by adding $\mathrm{Cu}$ to aluminum alloys, because $\mathrm{Cu}$ suppressed formation and growth of a reaction layer. Moreover, the effect was much larger by $\mathrm{Cu}$ and $\mathrm{Si}$ combined addition. The fracture for the joints with higher strength occurred within the base aluminum alloys. As a reaction layer is thicker, the fracture mode was changed from an interfacial fracture to an aluminum alloy matrix and a reaction layer fracture, regardless of containing copper. For all investigated alloys, the highest joint strength was obtained in a certain value of reaction layer thickness, in particular, the optimum thickness value with the highest joint strength for $\mathrm{Cu}$ and $\mathrm{Si}$ combined alloy was smallest. By $\mathrm{Cu}$ and $\mathrm{Si}$ combined addition, our proposed guideline of the interfacial structure to obtain the joints strength more than $70 \mathrm{MPa}$ was satisfied more easily. It was concluded that alloying of both $\mathrm{Cu}$ and $\mathrm{Si}$ to aluminum alloys improves the bondability of the joints.
\end{abstract}

Key Words: Dissimilar metal joints of aluminum alloys to steels, Solid-state diffusion bonding, Alloying elements, Interfacial fracture, Reaction layer

\section{Introduction}

Since Kyoto Protocol which regulates the emission of greenhouse gas was adopted, the reduction of gas consumption of cars has been emphasized around the world. One of the useful processes to improve gas consumption is reducing car weight. To reduce car weight, materials lighter than steels have been used in car bodies like aluminum alloys or magnesium alloys ${ }^{1)}$. Industrially, dissimilar metal joints of aluminum alloys and steels have been applied partially to automobile bodies using rivets. To accomplish lighter weight of cars and lower cost of their joints, many studies on the metallurgical bonding of aluminum alloys and steels have been reported, however, the study for evaluating the effects of alloying elements on bondability of their joints has not been sufficiently conducted. In particular, although the effect of $\mathrm{Cu}$ on improving joint strength had been partly confirmed ${ }^{2}$, the mechanism of the joint strength with $\mathrm{Cu}$ had not been clarified.

In this study, we investigated the effect of $\mathrm{Cu}$ addition in aluminum alloy on bondability of the dissimilar metal joints using diffusion bonding.

\footnotetext{
${ }^{*}$ Received: 2008.11 .18

${ }^{* *}$ Student Member, Division of Materials and Manufacturing Science, Graduate school of Engineering, Osaka University, Osaka, Japan

${ }^{* * *}$ Student Member, Division of Materials and Manufacturing Science, Graduate school of Engineering, Osaka University, Osaka, Japan (now Komatsu Ltd.)

${ }^{* * * *}$ Member, Division of Materials and Manufacturing Science, Graduate school of Engineering, Osaka University, Osaka, Japan
}

\section{Experimental procedures}

Table 1 shows the chemical compositions of materials used in this study. A cold rolled steel (SPCE) containing few alloying elements and four types of aluminum alloys, A2 (Si: 0.6, Cu: 0(in wt. \%)), AC (Si: 0.6, Cu: 1.0), C2 (Si: 1.5, Cu: 0), CC (Si: 1.5, $\mathrm{Cu}: 1.0)$ were used.

Table 1 Chemical composition of specimens.

(a) Aluminum alloys

\begin{tabular}{|c|c|c|c|c|c|c|c|c|c|}
\hline \multirow{2}{*}{ material } & \multicolumn{10}{|c|}{ Chemical composition (mass\%) } \\
\cline { 2 - 11 } & $\mathrm{Mg}$ & $\mathrm{Si}$ & $\mathrm{Fe}$ & $\mathrm{Cu}$ & $\mathrm{Cr}$ & $\mathrm{Mn}$ & $\mathrm{Zn}$ & $\mathrm{Ti}$ & $\mathrm{Al}$ \\
\hline \hline $\mathrm{A} 2$ & 0.6 & 0.6 & 0.18 & - & - & 0.07 & - & 0.02 & Bal. \\
\hline $\mathrm{C} 2$ & 0.6 & 1.5 & 0.18 & - & - & 0.07 & - & 0.02 & Bal. \\
\hline $\mathrm{AC}$ & 0.6 & 0.6 & - & 1.0 & - & - & - & - & Bal. \\
\hline $\mathrm{CC}$ & 0.6 & 1.5 & - & 1.0 & - & - & - & - & Bal. \\
\hline
\end{tabular}

(b) Steel

\begin{tabular}{|c|c|c|c|c|c|c|}
\hline \multirow{2}{*}{ material } & \multicolumn{6}{|c|}{ Chemical composition (mass\%) } \\
\cline { 2 - 7 } & $\mathrm{C}$ & $\mathrm{Mn}$ & $\mathrm{Si}$ & $\mathrm{P}$ & $\mathrm{S}$ & $\mathrm{Fe}$ \\
\hline \hline SPCE & 0.01 & 0.15 & 0.01 & 0.012 & 0.005 & Bal. \\
\hline
\end{tabular}

Joints of this bonding experiment consisted of a plate steel sandwiched between two cylindrical aluminum alloys. The original oxide films on the surface of specimens were eliminated by a series of treatments including grinding with emery papers, acetone cleaning, and drying during 1 hour. After these treatments, diffusion bonding was immediately carried out in a vacuum of $1.0 \times 10^{-2} \mathrm{~Pa}$ at heating temperatures ranging from 773 to $823 \mathrm{~K}$ for a holding time from 300 to $1800 \mathrm{~s}$ with a pressure of $2.5 \mathrm{MPa}$. The heating rate was $3 \mathrm{~K} / \mathrm{s}$. 
The interface of joints was analyzed by using scanning electron microscope (SEM), electron probe microanalysis (EPMA), and transmission electron microscope (TEM). The thickness of the reaction layer at the bonded interface was measured using SEM image. The three images for each sample were randomly taken in the center of a bonded interface and twenty measurement of the reaction layer thickness for each picture were made at even intervals with image processing software. Then, the average value of thickness of the reaction layer was calculated from sixty measurements for each sample.

The equation (1) was used to evaluate the fraction of un-bonded region at the bonded interface ( $\mathrm{Fr})$. The region where the reaction layer formed and the region where the reaction layer was not observed were defined as bonded region (A) and un-bonded region (B), respectively.

$$
F r=\sum B /\left(\sum A+\sum B\right)
$$

Tensile tests at room temperature were performed to measure the tensile strength of bonded joint. The test was performed using a Instron type tensile testing machine. The cross-head speed was $3.0 \times 10^{-2} \mathrm{~mm} / \mathrm{s}$.

\section{Result and discussion}

\subsection{Interfacial reaction layer}

To investigate the effect of $\mathrm{Cu}$ on the interfacial reaction layer, microstructure observation and composition analysis were performed. Typical backscattering electron images (BEI) for the cross-sections of the diffusion couples with bonding temperature (T) of $785 \mathrm{~K}$ and bonding time (t) of $1800 \mathrm{~s}$ are shown in Fig. 1. A gray colored interfacial reaction layer with a thickness of several $\mu \mathrm{m}(3-5 \mu \mathrm{m})$ formed at the Al alloy/SPCE interface in Fig. 1. To identify chemical composition at the interfacial reaction layer, we performed point analysis at the each points of Fig. 1. The result of this point analysis is shown in Table 2. According to past investigations ${ }^{3)}$ and a phase diagram of the binary $\mathrm{Fe}-\mathrm{Al}$ system $^{4}$, the interfacial reaction layers on the steel (SPCE) side (points of odd numbers) was estimated to be $\mathrm{Fe}_{2} \mathrm{Al}_{5}$. The interfacial reaction layer on the A2 side was estimated to be $\mathrm{FeAl}_{3}$. The result of TEM analyses at the $\mathrm{C} 2$ side is shown at Fig. 2. From Fig. 2, the interfacial reaction layer on the $\mathrm{C} 2$ side was found to be $\mathrm{Al}_{12} \mathrm{Fe}_{3} \mathrm{Si}$. Similarly, the point analysis showed that the interfacial reaction layers on the $\mathrm{AC}$ and $\mathrm{CC}$ sides were ternary Al-Fe-Si IMC containing $\mathrm{Cu}$.

At the interfacial reaction layer, EPMA was performed. The result of this analysis is shown in Fig. 3. At the areas where the existence of ternary Al-Fe-Si IMC containing $\mathrm{Cu}$ was estimated, the segregations of $\mathrm{Si}$ and $\mathrm{Cu}$ was confirmed.

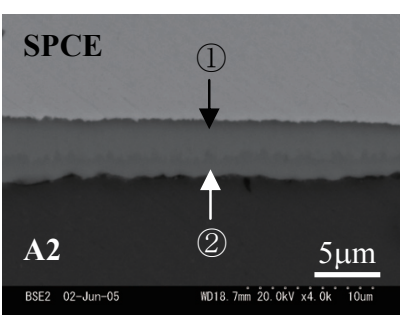

(a) A2-SPCE

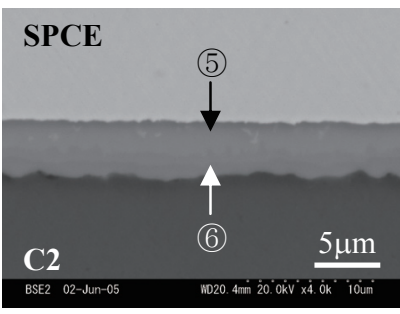

(c) $\mathrm{C} 2$-SPCE

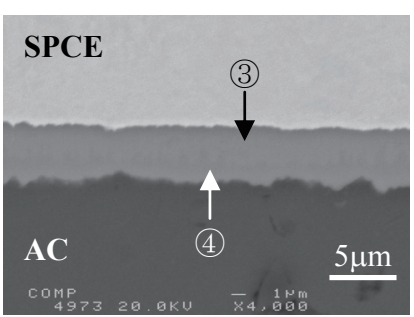

(b) AC-SPCE

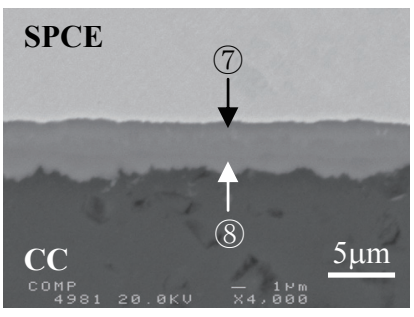

(d) $\mathrm{CC}-\mathrm{SPCE}$
Fig. 1 BEI of the interface in $\mathrm{Al}$ alloy/steel joint bonded at $785 \mathrm{~K}$ for $1800 \mathrm{~s}$

Table 2 EPMA quantitative analysis of each point in Fig. 1.

\begin{tabular}{|c|c|r|r|r|r|r|}
\hline \multicolumn{2}{|c|}{} & \multicolumn{6}{|c|}{ Chemical composition (mol\%) } \\
\hline Sample & Point & \multicolumn{1}{|c|}{$\mathrm{Fe}$} & $\mathrm{Al}$ & $\mathrm{Si}$ & $\mathrm{Mg}$ & $\mathrm{Cu}$ \\
\hline \multirow{2}{*}{ A2-SPCE } & 1 & 23.1 & 74.6 & 2.3 & 0.02 & - \\
\cline { 2 - 8 } & $(2)$ & 20.8 & 77.0 & 2.0 & 0.12 & - \\
\hline \multirow{2}{*}{ AC-SPCE } & 3 & 25.6 & 72.6 & 1.7 & 0.0 & 0.1 \\
\cline { 2 - 8 } & $(4)$ & 21.7 & 76.2 & 1.5 & 0.4 & 0.3 \\
\hline \multirow{2}{*}{ C2-SPCE } & 5 & 25.3 & 70.7 & 3.9 & 0.03 & - \\
\cline { 2 - 8 } & 6 & 16.8 & 72.5 & 10.0 & 0.72 & - \\
\hline \multirow{2}{*}{ CC-SPCE } & 7 & 25.8 & 71.6 & 2.6 & 0.0 & - \\
\cline { 2 - 8 } & 8 & 16.4 & 73.8 & 7.6 & 0.1 & 2.1 \\
\hline
\end{tabular}

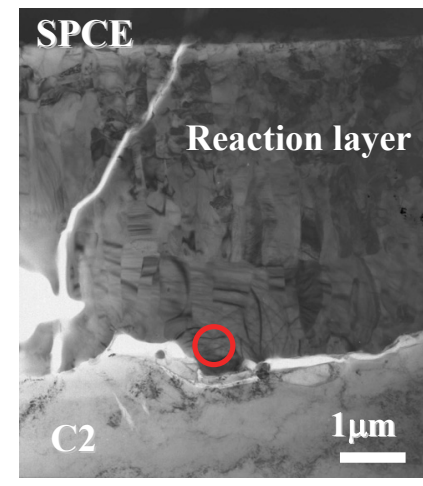

(a) Bright-field image

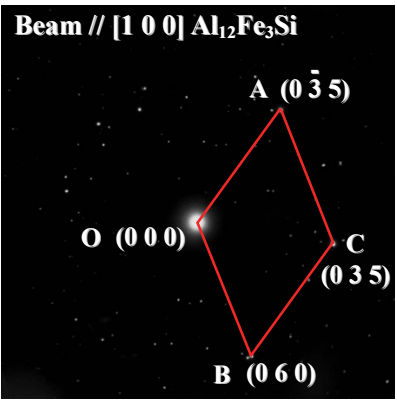

(b) Diffraction pattern
Fig. 2 TEM image and corresponding diffraction pattern at the interface in $\mathrm{C} 2$ /SPCE joint bonded at $798 \mathrm{~K}$ for $1800 \mathrm{~s}$. 


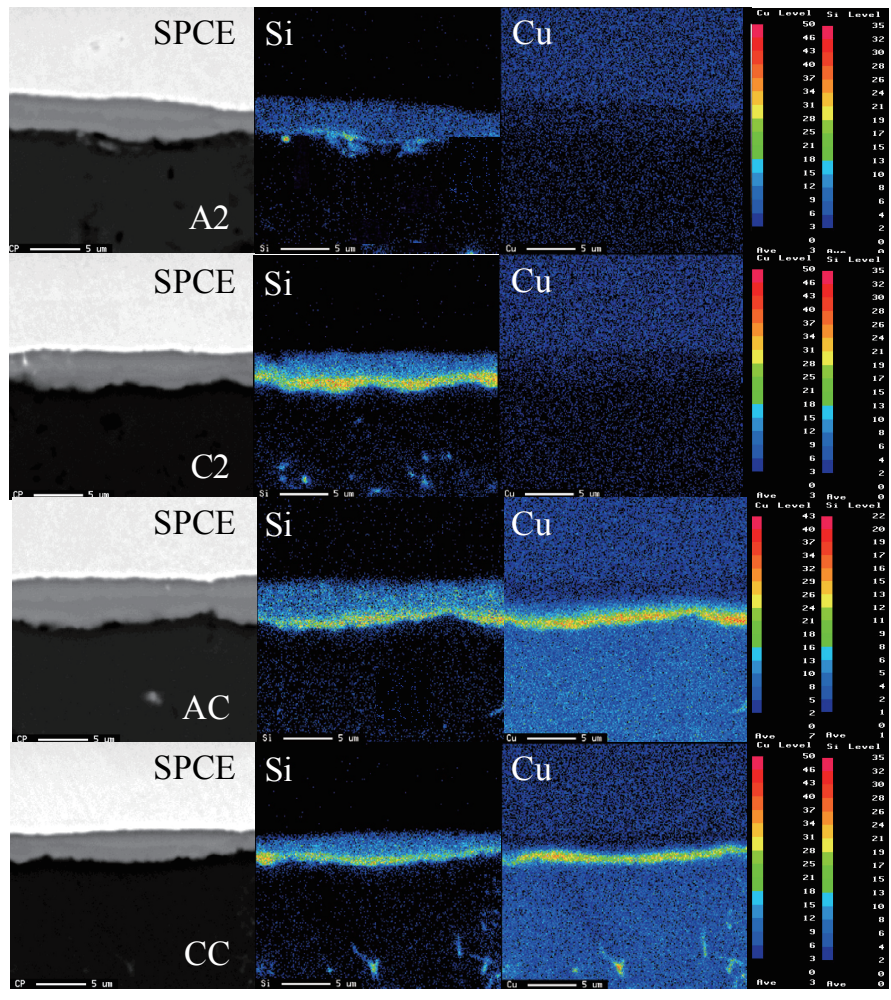

Fig. 3 EPMA mapping analysis of the interface in $\mathrm{Al}$ alloy/steel joint bonded at $785 \mathrm{~K}$ for $1800 \mathrm{~s}$.

\subsection{Joint strength and thickness of reaction layer}

The relationship between tensile strength and mean thickness of reaction layer is shown in Fig. 4. The mean thickness of the reaction layer was estimated by the method described in experimental procedure. As shown in Fig. 4, high joint strength was obtained in a certain range of the reaction layer thickness. Both the much thinner reaction layer and the thicker reaction layer caused the decrease of joint strength.

The fracture surface for the joints with higher strength occurred within an aluminum alloy matrix as shown in Fig. 5 and Table 3. As a reaction layer is thicker, the fracture mode was changed from an interfacial fracture to an aluminum alloy matrix and a reaction layer fracture regardless of containing $\mathrm{Cu}$. Furthermore, by combined addition $\mathrm{Cu}$ and $\mathrm{Si}$ to aluminum alloys, joint strength was improved and the optimum thickness value with the highest joint strength was thinner. On these effects of combined addition of $\mathrm{Cu}$ and $\mathrm{Si}$, the studies have reported that a ternary $\mathrm{Al}-\mathrm{Fe}-\mathrm{Si} \mathrm{IMC}$ contributes to firming thin and uniform reaction layer ${ }^{5}$. In this study, $\mathrm{Cu}$ in aluminum alloy accelerated forming a ternary $\mathrm{Al}-\mathrm{Fe}-\mathrm{Si} \mathrm{IMC}$ and it was estimated that this ternary IMC conduced to high joint strength.

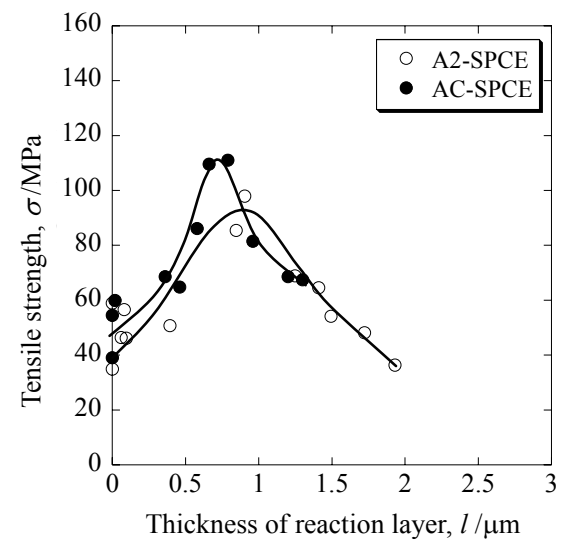

(a) Low silicon

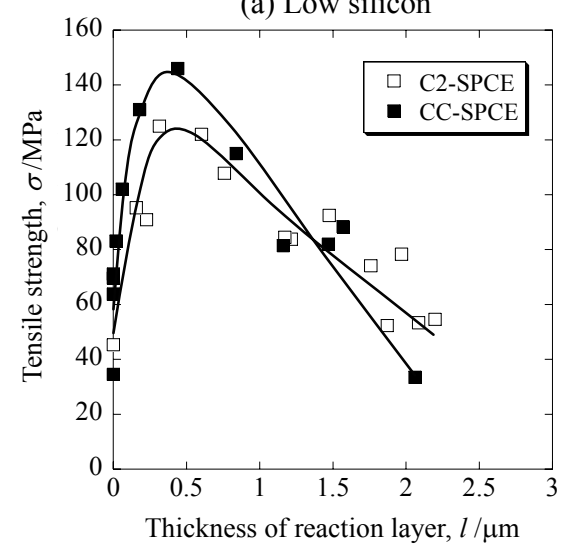

(b) High silicon

Fig. 4 Effect of cupper on tensile strength.

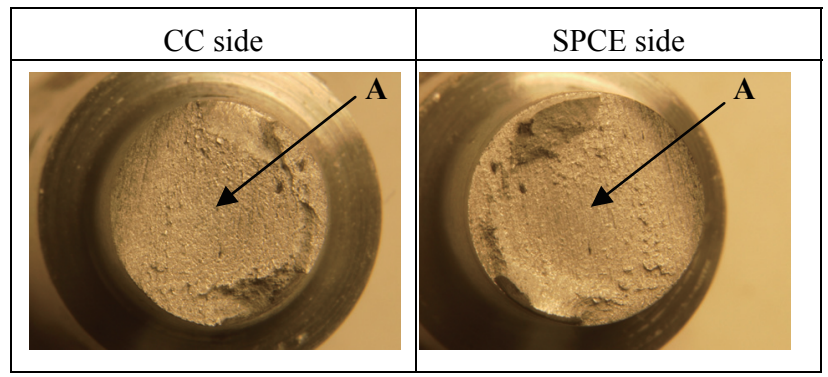

(a) Macro scale

$50 \mathrm{~mm}$

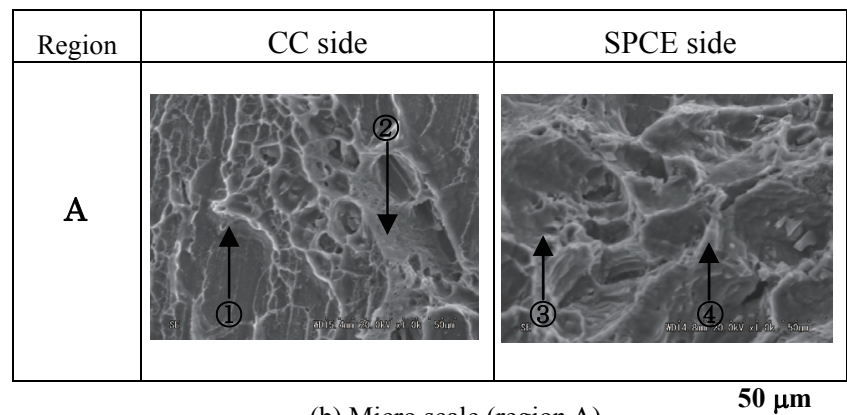

(b) Micro scale (region A)

Fig. 5 SEM image of fracture surface of CC/SPCE joint

(Thickness of reaction layer: $0.44 \mu \mathrm{m}$, Tensile strength: $146 \mathrm{MPa}$ ).

Table 3 EDX quantitative analysis of point (1) to (4) in Fig. 5 (b).

\begin{tabular}{|c|c|r|r|r|r|}
\hline point & \multicolumn{1}{|c|}{$\mathrm{Al}$} & \multicolumn{1}{c|}{$\mathrm{Fe}$} & \multicolumn{1}{c|}{$\mathrm{Mg}$} & \multicolumn{1}{c|}{$\mathrm{Si}$} & \multicolumn{1}{c|}{$\mathrm{Cu}$} \\
\hline \hline$(1)$ & 96.95 & 0.07 & 1.49 & 1.19 & 0.29 \\
\hline$(2)$ & 96.40 & 0.14 & 1.27 & 1.55 & 0.64 \\
\hline 3 & 95.14 & 0.67 & 1.37 & 2.29 & 0.53 \\
\hline$(4)$ & 96.97 & 0.47 & 1.46 & 0.66 & 0.44 \\
\hline
\end{tabular}




\subsection{Fraction of un-boned region}

As mentioned in section 3.2, thin and uniform reaction layer contributes high joint strength. On formation of the interfacial reaction layer, we investigated the relationship between thickness of reaction layer and fraction of un-bonded region at interface about each joint. The results are shown in Fig. 6. Fraction of un-bonded region decrease as a reaction layer is thicker. Moreover, adding $\mathrm{Cu}$ to aluminum alloys promoted decrease of this fraction. It was suggested that adding $\mathrm{Cu}$ to aluminum alloy accelerates the formation of a ternary Al-Fe-Si IMC, and this ternary IMC decreased fraction of un-bonded region, consequently improved joint strength. This effect was remarked for the joint of aluminum alloy adding $\mathrm{Si}$ and $\mathrm{Cu}$ combined.

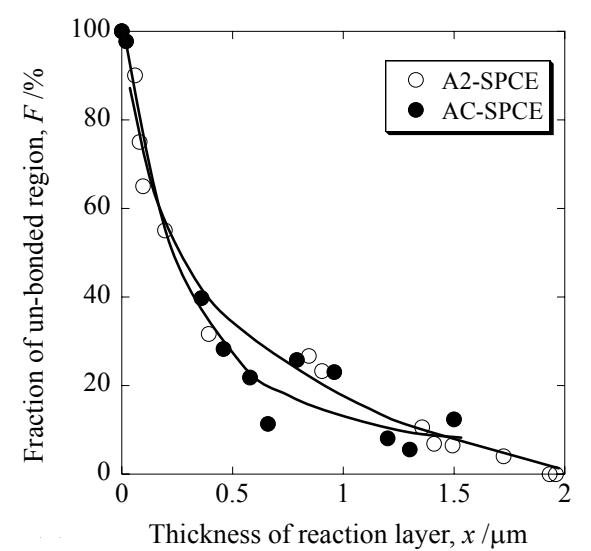

(a) Low silicon

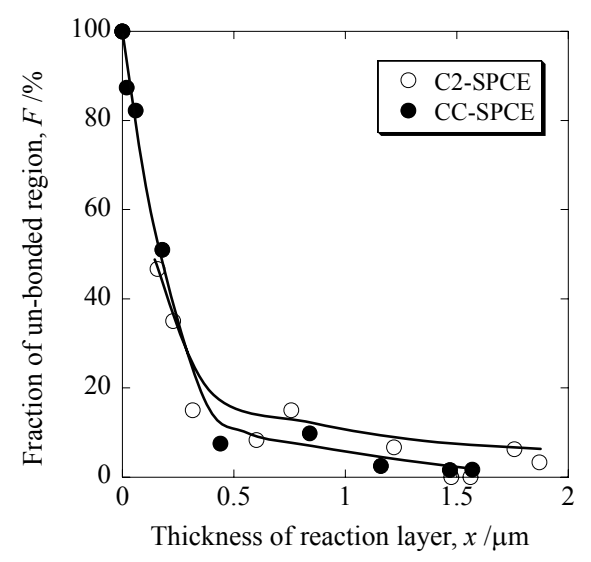

(b) High silicon

Fig. 6 Effect of $\mathrm{Cu}$ on fraction of un-bonded region.

\subsection{Range of IMC thickness to obtain $70 \mathrm{MPa}$ in tensile strength}

The value of tensile strength was superimposed on the graph of the correlation between thickness of reaction layer and fraction of un-bonded region as shown in Fig. 7. Circles in Fig. 7 shows joint strength higher than $70 \mathrm{MPa}$ and are ranged as shown in Table 4. Higher tensile strength joints tended to distribute at the lower-left corner of the graph. This indicates that formation of thin and uniform reaction layer and low fraction of un-bonded region led to high joint strength. Thus, we draw the guideline to obtain high strength of the joints; i.e. the thickness of the reaction layer less than $1.5 \mu \mathrm{m}$ and fraction of un-bonded region less than $30 \%$. When this guideline of interfacial condition is satisfied, joint strength higher than $70 \mathrm{MPa}$ can be obtained. Furthermore, we read off the value of reaction layer thickness at intersection of the guideline and approximate line of interfacial structure. The estimated value is listed in Table 5. Adding $\mathrm{Cu}$ to aluminum alloy broadened the range of reaction layer to obtain joint strength higher than $70 \mathrm{MPa}$. Moreover, for the joint of aluminum alloy of $\mathrm{Si}$ and $\mathrm{Cu}$ combined addition, the range was broadest. This broadening means that reaction layer to obtain joint strength higher than $70 \mathrm{MPa}$ can be easily controlled. Consequently, these results also show that alloying of both $\mathrm{Cu}$ and $\mathrm{Si}$ to aluminum alloys improves the bondability of the joints.

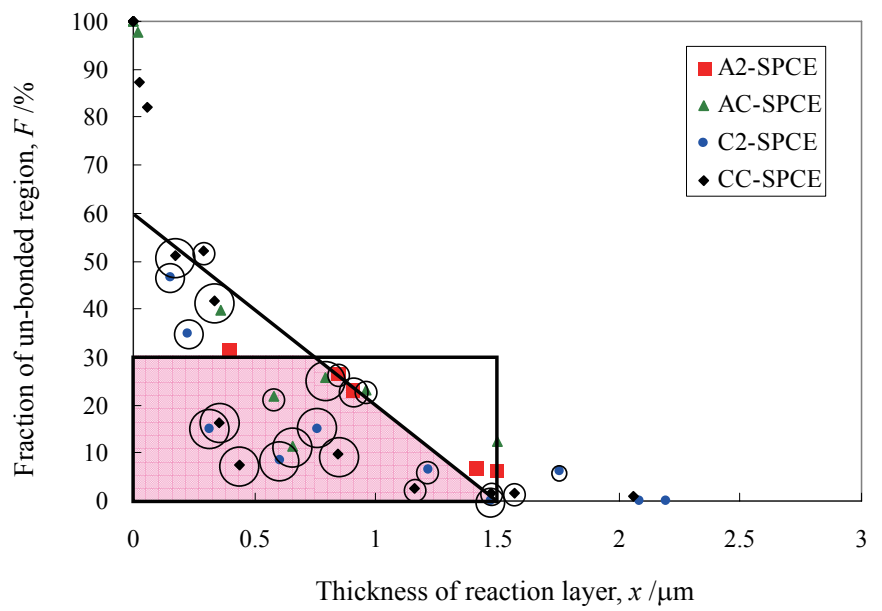

Fig. 7 Guideline of reaction layer to obtain joint strength higher than $70 \mathrm{MPa}$.

Table 4 Relationship between tensile strength and mark in Fig. 7.

\begin{tabular}{|c|c|c|c|c|c|}
\hline Tensile strength (MPa) & $\sim 70$ & $70 \sim 80$ & $80 \sim 90$ & $90 \sim 100$ & $100 \sim$ \\
\hline Mark & No circle & $\bigcirc$ & $\bigcirc$ & $\bigcirc$ & $\bigcirc$ \\
\hline
\end{tabular}

Table 5 Range of IMC thickness to obtain 70MPa in tensile strength.

\begin{tabular}{|c|c|}
\hline & Range of IMC thickness \\
\hline A2-SPCE & $0.60 \mu \mathrm{m} \sim 1.10 \mu \mathrm{m}$ \\
\hline AC-SPCE & $0.50 \mu \mathrm{m} \sim 1.20 \mu \mathrm{m}$ \\
\hline C2-SPCE & $0.30 \mu \mathrm{m} \sim 1.45 \mu \mathrm{m}$ \\
\hline CC-SPCE & $0.20 \mu \mathrm{m} \sim 1.45 \mu \mathrm{m}$ \\
\hline
\end{tabular}




\section{Conclusions}

From the correlation of the interfacial reaction layer and tensile strength, the effect of $\mathrm{Cu}$ on interfacial reaction layer and joint strength of dissimilar metal joints of aluminum alloys and steels has been evaluated.

At the interface of the joint of aluminum alloy containing 1.0 wt. \% $\mathrm{Cu}$, formation of a ternary Al-Fe-Si IMC was confirmed. It was suggested that adding $\mathrm{Cu}$ to aluminum alloys accelerated the formation of a ternary IMC at interfacial reaction layer. The ternary IMC contributes the growth of thin and uniform reaction layer, and leads to the improvement of the joint strength. Furthermore, the highest joint strength was obtained for the joint of aluminum alloys adding combined $\mathrm{Si}(1.5 \mathrm{wt}$. \%) and $\mathrm{Cu}$.

We confirmed adding $\mathrm{Cu}$ broadens the range of reaction layer to obtain joint strength higher than $70 \mathrm{MPa}$. This broadening was clearly larger by $\mathrm{Cu}$ and $\mathrm{Si}$ combined contained. It can be concluded that adding $\mathrm{Cu}$ to aluminum alloy improves the bondability of dissimilar metal joints of aluminum alloys and steels and the best bondability was obtained for the joint of aluminum alloys containing Si (1.5 wt. \%) and $\mathrm{Cu}(1.0$ wt. \%) in this study.

\section{Acknowledgement}

This study was supported by Priority Assistance for the Formation of Worldwide Renowned Centers of Research - The Global COE Program (Project: Center of Excellence for Advanced Structural and Functional Materials Design) from the Ministry of Education, Culture, Sports, Science and Technology (MEXT), Japan.

\section{Reference}

1) W. S. Miller, L. Zhuang, J. Bottema, A. J. Wittebrood, P. De Smet, A. Haszler and A. Vieregge, Recent development in aluminum alloys for the automotive industry, Materials Science and Engineering A, 280-15(2000), 37-49

2) V. V. Truntnev, Diffusion welding of austenitic steel to aluminum alloys, Welding Production., 14-10(1967), 18-23.

3) Akio Hirose, Fumiaki Matsui, Hirotaka Imaeda and Kojiro F. Kobayashi, Interfacial reaction and strength of dissimilar joints of aluminum alloys to steels for automobile, Materials Science Forum, Vols. 475-479 (2005), 349-352

4) The Japan Institute of Metals, METAL DATA BOOK, Maruzen (1993), 471

5) Hidetaka Umeshita, Hiroki Imaeda, Akio Hirose and Kojiro F. Kobayashi, Effects of alloying elements on interfacial properties of dissimilar joint of aluminum alloy and steels, Smart Processing Technology, Osaka(2006), 199-202 